\title{
EDITORIAL
}

\section{INDEXACIÓN: te queremos aunque nos desprecies}

$\mathrm{E}$ n tiempos de la posguerra, por los años cincuenta, el gobierno de los Estados Unidos empezó a destinar ingentes sumas de dinero para que investigadores calificados desarrollaran la tecnología, registraran patentes y contribuyeran al crecimiento económico y al bienestar de sus gentes. Como la mejor forma de mostrar los resultados era dándolos a conocer en publicaciones periódicas de reconocido prestigio, se volvió popular la frase "publique o perezca" (publish or perish); la consecución o renovación de las partidas de dinero asignadas (conocidas como grants) dependía del prestigio logrado por los científicos a través de dichas publicaciones, así se perpetuaba un ciclo que permitía la supervivencia de universidades y docentes.

Las revistas científicas eran pocas y su fama corría de boca en boca. Sin embargo, con pocas excepciones era muy difícil conseguir la inserción de los artículos en las más famosas, sobre todo si se quería hacer rápidamente. Así se acudía a otras consideradas oscuras, lo que por ejemplo permitió que de manera rápida Banting y Best dieran a conocer al mundo el descubrimiento de la insulina, dirigiéndose al Canadian Medical Association Journal, y no al reconocido Journal of the American Medical Association, con oficinas por demás cercanas. Paulesco -en la Europa Oriental- parece que había hecho antes el hallazgo de la hormona hipoglucemiante, pero lo publicó en una revista impresa en idioma local que nadie en occidente conocía, y el crédito se lo llevaron los primeros. En la época de Addison (siglo XIX) existía el British Medical Journal, que no consideró de importancia su casuística de casos de anemia pigmentada (que incluía pacientes con insuficiencia suprarrenal crónica y anemia perniciosa), lo que llevó al autor a imprimirlo en forma de libro, que fácilmente se puede ver ahora en el ciberespacio. Si Addison era uno de los cuatro grandes del Guys Hospital ¿qué podrían esperar los demás?

El acúmulo de conocimientos condujo a un problema adicional: ¿Cómo encontrar las investigaciones previas, conocer sus características y acceder a ellas? Si se encontraban en el New England Journal of Medicine, eso no representaba ningún problema. Pero el número de revistas acreditadas crecía y se hizo necesario catalogar los artículos en volúmenes -valga la redundancia- muy voluminosos, como recordamos aquellos del Index Medicus. Empresas editoriales gigantes como Thompson-Reuters y la holandesa Elsevier (que publicaba la Excerpta Medica) empezaron a desarrollar fórmulas o índices que permitían medir la importancia, visibilidad, índices de citación y el impacto de los trabajos publicados en las diferentes revistas. Estas comenzaron a indexarse (indizarse es más castizo), pero no sólo por el bien de la ciencia, sino porque era un gigantesco negocio para editoriales, autores, universidades y otros.

Desde la entrada en vigencia del decreto 1279 de junio 19 de 2002, Colciencias inició un proceso de indexación de las revistas científicas y otras de orden académico, adicionando una lenta homologación de las revistas extranjeras. Si bien pocas publicaciones seriadas atendieron en un principio la convocatoria de la entidad rectora en ciencia y tecnología, esta participación fue creciendo en los últimos años; la intervención tuvo un efecto positivo en la calidad y flujo de artículos para las revistas nacionales, pero volteó la pirámide al aumentar el número de publicaciones seriadas ubicadas en las categorías más altas. Esto quiere decir que los docentes de las universidades públicas (y de algunas privadas) lograron mejorar sus ingresos, teniendo como base la productividad científica y un acceso más fácil a publicaciones nacionales en categorías A1 y A2, que mejoraron en calidad y en cantidad. Aunque la publicación de trabajos de investigación en las revistas mejor calificadas es sólo uno de los cuatro factores tenidos en cuenta para calcular los sueldos, éste resulta ser el más dinámico. Entre mejor categorizada está la revista, más puntos se logran y más dinero se gana.

Los trabajos más tenidos en cuenta son las investigaciones originales, metanálisis y revisiones sistemáticas, y artículos de reflexión derivados de la investigación. Un porcentaje menor del puntaje se aplica a revisiones de tema, casos clínicos, cartas al editor y artículos de reflexión publicados en revistas especializadas indexadas u homologadas por Colciencias.

Lo positivo de esta regulación -además de mejorar los ingresos de los investigadores nacionales- se observó cuando las publicaciones seriadas aplicaron el procedimiento de valoración por los árbitros, fueron abandonando la endogamia característica (los autores son las mismas personas pertenecientes a los comités editoriales y científicos) y empezaron a tener muy en cuenta maestrías, doctorados y posdoctorados de autores, comités y árbitros; lentamente ha habido un giro hacia la publicación de artículos en inglés, a abandonar los medios impresos, costosos, de escaso impacto, poca lectura, con colecciones que ocupan espacio y se llenan de polvo, y que contribuyen al daño climático. Lo moderno es la revista virtual de acceso abierto, incluida en texto completo en las mejores bases de datos, y con programas diseñados para facilitar la administración de la revista que facilitan el flujo de artículos remitidos para evaluación. 
Ha sido usual que las instituciones académicas, hospitalarias y asociaciones científicas colombianas tengan su propio órgano informativo donde se publican trabajos de congresos, revisiones y casos clínicos interesantes. La función de los profesores en docencia, asistencia e investigación se ha escindido (a unos se les paga por atender pacientes, a otros por enseñar y a los que investigan, por publicar). La comunidad científica y Colciencias han tenido desencuentros relacionados con políticas sobre ciencia y tecnología; esta última ha denunciado casos de proyectos con resultados de baja calidad, algunos con plagios o falsedades, publicados en "revistas que nadie lee", hecho denominado "ciencia perdida".

La calidad de las tesis de pregrado, maestrías y doctorados es variable. Como se escriben con metodología de tesis y se colocan en internet en los denominados repositorios virtuales institucionales, no se hace el esfuerzo de adaptar estos resultados al formato de artículo científico, si no es necesario o no hay un estímulo. Es la llamada literatura gris.

Para bien o para mal, se hace necesaria la inserción en el mundo globalizado. La libre circulación de personas, el intercambio de información, los tratados de libre comercio y el posible ingreso a la OCCDE (asociación de los 34 países de más desarrollo), afecta también a los investigadores y a los editores. De todos es sabido que esta última y muy poderosa institución exige homologación mundial. Ya no podremos compararnos con nosotros mismos ni con la región. Aunque todavía no se ha implementado el proceso, seremos los enanitos del paseo, pues quedaremos nivelados por lo bajo. Será un adiós a los puntos relativamente fáciles de antes. Habrá que apuntarle a las muy complicadas de alto nivel, y escribir los artículos en inglés. Como las universidades públicas se ven obligadas a aumentar anualmente los salarios de sus investigadores de acuerdo con los puntos logrados, es posible que ese gasto disminuya cuando publiquen en nuestras revistas que forzosamente bajarán de categoría.

La resolución 278 de abril 12 de 2014 expedida por Colciencias pone en vigencia la nueva forma de medición de grupos académicos, investigadores individuales, revistas, editoriales productoras de libros y, por ende, de las universidades que albergan investigadores, grupos y editoriales. Estos se clasificarán en A1, A, B, C y D, dependiendo de que los trabajos resultantes de sus investigaciones sean aceptados por revistas (o editados en forma de libros o capítulos) en editoriales con idénticas clasificaciones. De esta manera, y para cumplir con los requisitos internacionales, nuestras revistas serán indexadas según el "factor de impacto" (rapidez, frecuencia y calidad de citaciones de los artículos) lo que generalmente es sinónimo de un verdadero aporte científico. El listado resultante se divide en 4 cuartiles (del Journal of Citation Report del "portal de conocimiento", Web of Science o WoS) de Thompson-Reuters antiguamente llamado Instituto de Información Científica (ISI), por su sigla en inglés; se tiene en cuenta además la medición de Scopus (de Elsevier), que mide este y otros parámetros en el posicionamiento de las revistas científicas (Scimago Journal Ranking o SJR). Por ahora estamos atenidos a Publindex (proyecto actual de Colciencias) que verifica contenidos de las publicaciones, pero no su calidad. Estas verificaciones locales con miras a la indexación migrarán hacia las de Scopus y el WoS, muy exigentes en sus requisitos, que sólo pocas de nuestras revistas llenan. En cuanto al índice de citación bibliográfica que debería escoger un investigador, SCOPUS incluye un mayor número de revistas de menor impacto, pero su análisis de citas es más rápido que el de WoS; en cambio, el de WoS es más detallado y la mayoría de las revistas están en inglés. Otra alternativa es el Google Académico, con características distintas a las anteriores. La presencia en una base de datos como LILACS permite la indización en el Google Scholar. Pero LILACS ha cambiado, y ahora tiene comité de selección con más requisitos.

Colombia tiene 52 revistas entre las 15.000 o más de Scopus a nivel mundial, y apenas 19 entre las 9.300 de WoS/ISI. Estos índices le permiten saber a un investigador si alguien lo lee y lo cita, lo cual es un medidor del impacto de su trabajo. Publindex tiene 544 revistas indexadas en su base de datos, que Colciencias ha venido utilizando para clasificar las publicaciones nacionales seleccionadas. Con la nueva medición, esta situación cambiará radicalmente. Por ejemplo, la única revista relacionada con ciencias sociales o de salud que está en este momento en Q1 (cuartil 1, o 25\% de la parte superior de la lista) es Vniversitas Psychologica de la Universidad Javeriana. Esta revista recibe 500 artículos anuales, de los cuales se seleccionan cerca del 20\% y se rechazan los restantes. Algunas que ahora indexa Publindex como A1, se posicionan en cuartiles entre 2 y 4. Entre las A2 actuales, las mejor libradas están en Q4 y otras ni siquiera, por lo que algunas quedarían en $\mathrm{B}$ o en $\mathrm{C}$ de la nueva clasificación. Las actuales B y C deben aspirar a una nueva categoría D, que implica estar al menos en dos bases de datos, que para ciencias de la salud serían el actual LILACS (con comité de selección), Redalyc de México, o las del grupo SciELO, además del Medline/Pubmed. Recordemos eso sí, que las revistas no son un fin sino un medio y su papel aún está por redefinir.

“El nuevo criterio creará más de un problema para cientos de grupos de investigación. Uno de los efectos es que las revistas de universidades regionales que no están indexadas en ninguno de los dos índices (Scopus e ISI/WoS) van a quedar invisibles y, por lo tanto, también el trabajo de los investigadores que publican en ellas", dice el profesor Sergio Roncallo, al hacer un análisis de la situación que se nos viene. Los trabajos publicados en revistas D, y en aquellas que ni siquiera estén en esta última clasificación, serán considerados como difusión social de conocimiento, una categoría inferior. Los profesores 
universitarios que no publiquen en estas revistas así indexadas, no podrían dar el paso de profesor asistente a asociado, pues las universidades privadas otorgan más puntos para ascensos, si logran publicar en ellas. Con las nuevas normas es posible que se termine Publindex y se modifique SciELO.

La multinacional americana creadora del factor de impacto hizo un arreglo con SciELO Brazil, para crear el SciELO Citation Index para revistas latinoamericanas. Elsevier, con más sentido comercial, se ha abierto a las revistas de países menos desarrollados, aunque nos clasifican en niveles mucho más bajos. Si una revista quiere pertenecer al grupo editorial holandés, el más grande de Europa y el más antiguo del mundo, debe pagar una considerable suma de dólares anuales. A cambio de esto, venden cada artículo encriptado a razón de unos 30 dólares. Acceder a este modelo no garantiza ingresar al índice Scopus, que se rige por otros criterios.

Esta forma de negocio está en choque abierto con la iniciativa de acceso abierto a la información, (con formato para 0JS), bajo licencia de Creative Commons. Algunas revistas colombianas están por ahora en ambos modelos (de cobrar, a través de Elsevier, y de regalar, a través del OJS pero con la mira de cobrarles a los autores en un futuro entre 500 y 5.000 dólares por artículo publicado, como lo hace el Lancet Global Health. Los lectores pueden acceder a todo el contenido de manera gratuita, pero esa visibilidad la paga el autor.

El comunicado del Journal of Citation Reports que se basa en las revistas aceptadas por cuartiles en el 2012 muestra muy pocas publicaciones colombianas, y estas son generalmente de ciencias exactas y naturales o de ciencias sociales.

Nuestras mejores publicaciones seriadas están a menudo en puestos internacionales bajos. Nuestras revistas de menos vuelo -por llamarlas de alguna manera- también han progresado rápidamente al adoptar un modelo virtual (de acceso abierto) para reducir costos. Algunas han logrado ubicarse en bases de datos importantes en nuestro medio (SciELO, Redalyc y BBCS-Lilacs) con incremento de su visibilidad y del flujo de trabajos provenientes de otras instituciones nacionales e internacionales. Ya no es raro entre nosotros ver artículos en inglés (como en Colombia Médica). El proceso de arbitraje, aunque no exento de críticas, ha sido de indudable ayuda para editores que buscan mejorar la calidad de los artículos; igual ocurre con la creciente "exogamia", es decir, la apertura a la aceptación de investigaciones procedentes de instituciones diferentes a la entidad editora, a veces ubicadas en países lejanos. También se observa cómo universidades de menor nivel empiezan a mejorar (y a publicar) sus resultados de investigación.

No es raro ver nuevos títulos de revistas mientras que otros han logrado mantenerse con pocos gastos, gracias a su manejo por voluntarios y al bajo costo que ofrece el ambiente cibernético. Pero las ilusiones iniciales pueden evaporarse con el nuevo remezón en la competencia global. Con la ilusión de avanzar en el ranking mundial, hacemos fila apretujados para conseguir la indexación, así sea modesta. Siempre nos queda la difusión social del conocimiento, pero esta no sirve para ascensos académicos.

El nuevo enfoque editorial cumple una labor pedagógica muy importante, porque a punta de revisiones, modificaciones o rechazos, autores inexpertos empiezan a preocuparse por el adecuado diseño de sus trabajos que fortalezca sus resultados, por escribir de manera apropiada, por lograr una adecuada discusión y basarse en referencias de calidad y muy actualizadas.

La difusión social del conocimiento, papel importante que jugarán muchas de nuestras revistas, no implica que estas deban bajar la guardia en los requisitos de publicación. La información que se brinde debe ser revisada con seriedad. No hacerlo nos llevaría -ahí sí- a la desaparición.

La Revista Colombiana de Endocrinología, Diabetes y Metabolismo se presentará en un futuro cercano a una convocatoria de Publindex-Colciencias, con el fin de ser medidos, y eventualmente indizados.

\section{Alfredo Jácome Roca, MD, FACP Internista-Endocrinólogo, Miembro del Comité Editorial}

